\title{
The Influence of Manufacturing Technology on the Properties of Chromium-Bronze Electrodes for Contact Relief Welding of Reinforcing Rods
}

\author{
Sergei L. Busygin*, Aleksandr M. Tokmin, \\ Nikolai N. Dovzhenko and Vladimir S. Kazakov \\ Siberian Federal University \\ Krasnoyarsk, Russian Federation
}

Received 30.10.2021, received in revised form 15.11.2021, accepted 11.12.2021

\begin{abstract}
The article discusses an effective, in comparison with common, technology of manufacturing chromium bronze electrodes for resistance projection welding of reinforcing bars. Within the framework of this technology, a method for preparing a melt with alloying with a multicomponent element, including basic elements, a matrix of copper powder and a filler of nanostructured chromium particles, is considered. The technology is based on a combined molding-plastic deformation process and makes it possible to obtain a finished resistance welding electrode of type $\mathrm{D}$ in one operation. The results of microstructural, X-ray micro-spectral and local energy dispersive (micro) analysis of electrode samples obtained by different technologies, explaining the main nature of the loss of electrode performance, are presented. The results of fractographic studies of the contact surface of the electrodes are considered. Electrical conductivity and mechanical properties were studied for all electrode samples. The results of tests on a resistance welding machine with an assessment of the wear of the electrodes and the reasons for their failure are presented.
\end{abstract}

Keywords: chromium bronze, electrodes for resistance projection welding, nanostructured particles, welding of fittings.

Acknowledgements. The work was carried out within the framework of the state assignment of the Ministry of Science and Higher Education of the Russian Federation (scientific topic code FSRZ-2020 0011).

Citation: Busygin, S.L., Tokmin, A.M., Dovzhenko, N.N., Kazakov, V. S. The influence of manufacturing technology on the properties of chromium-bronze electrodes for contact relief welding of reinforcing rods, J. Sib. Fed. Univ. Eng. \& Technol., 2021, 14(8), 914-929. DOI: 10.17516/1999-494X-0368

(C) Siberian Federal University. All rights reserved

This work is licensed under a Creative Commons Attribution-Non Commercial 4.0 International License (CC BY-NC 4.0).

* Corresponding author E-mail address: politex_1999@bk.ru 


\title{
Влияние технологии изготовления
}

\section{на свойства электродов из хромистой бронзы \\ для контактной рельефной сварки арматурных стержней}

\author{
С. Л. Бусыгин, А.М. Токмин, \\ Н.Н. Довженко, В.С. Казаков \\ Сибирский федеральный университет \\ Российская Федераџия, Красноярск
}

\begin{abstract}
Аннотация. В статье рассмотрена эффективная по сравнению с распространенными технология изготовления электродов из хромистой бронзы для контактной рельефной сварки арматурных стержней. В рамках этой технологии рассмотрен способ приготовления расплава с легированием мультикомпонентным элементом, включающим базовые элементы - матрицу из медного порошка и наполнитель из наноструктурированных частиц хрома. Технология основана на совмещенном процессе литье - пластическая деформация и позволяет за одну операцию получить готовый электрод контактной сварки типа D. Представлены результаты микроструктурного, микрорентгеноспектрального и локального энергодисперсионного (микро) анализа образцов электродов, полученных по разным технологиям, объясняющие основной характер потери работоспособности электродов. Рассмотрены результаты фрактографических исследований контактной поверхности электродов. Для всех образцов электродов исследованы электропроводность и механические свойства. Приведены результаты испытаний на машине контактной сварки с оценкой износа электродов и причины выхода их из строя.
\end{abstract}

Ключевые слова: хромистая бронза, электроды для контактной рельефной сварки, наноструктурированные частицы, сварка арматуры.

Благодарности. Работа выполнена в рамках государственного задания Министерства науки и высшего образования Российской Федерации (код научной темы FSRZ-2020-0011).

Цитирование: Бусыгин, С. Л. Влияние технологии изготовления на свойства электродов из хромистой бронзы для контактной рельефной сварки арматурных стержней / С. Л. Бусыгин, А. М. Токмин, Н. Н. Довженко, В. С. Казаков // Журн. Сиб. федер. ун-та. Техника и технологии, 2021, 14(8). С. 914-929. DOI: 10.17516/1999-494X-0368

\section{Введение}

Метод контактной сварки арматуры широко применяют при сборке каркасов железобетонных изделий и армирующих сеток. Технология основана на эффекте нагрева свариваемых деталей до температуры плавления в зоне их соединения без применения присадочных материалов. Нагрев деталей осуществляется энергией, выделяемой электрическим током в короткозамкнутом контуре. Необходимым условием для осуществления процесса сварки выступает более высокое электросопротивление на границе свариваемых частей изделия в зоне их контакта.

Электроды контактной сварки $[1,8]$ - это основной инструмент, технически осуществляющий процесс образования сварного соединения, они являются продолжением силового вторичного контура машины. Эти элементы подлежат замене после выхода их из строя (износа). Электроды выполняют три основные функции: передают давление при сжатии деталей, подводят к ним электрический ток и отводят тепло, выделяющееся в процессе сварки.

Среди многочисленных марок бронз $[2,3,7]$, применяемых для изготовления электродов, выделяется группа медных сплавов с малым (0,3-1 \%) содержанием легирующих элементов (кад- 
миевые, хромистоциркониевые, хромистые бронзы) [6]. Эти бронзы обладают близкой электрои теплопроводностью в сравнении с чистой медью. При этом они имеют большую твердость, предел текучести, износостойкость, циклическую долговечность и сохраняют работоспособность до более высоких температур за счет повышенной температуры рекристаллизации $[9,10]$.

В настоящее время в промышленности наиболее широкое распространение получили следующие технологии изготовления электродов контактной сварки:

- литье;

- холодное прессование;

- высокоскоростная штамповка;

- токарная обработка прутков.

Электроды, изготовленные по вышеперечисленным технологиям в процессе контактной сварки арматуры, имеют недостаточную эксплуатационную стойкость, поскольку деформируются (рис. la), быстро изнашиваются с загрязнением контактной поверхности (рис. $1 b$ ) и разрушаются (рис. 1c).

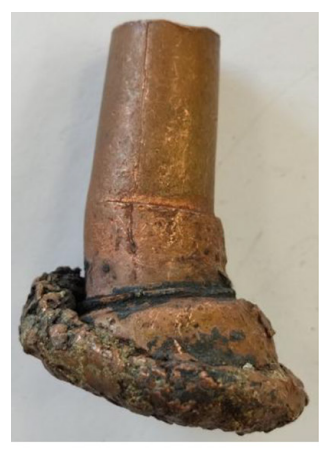

$a$

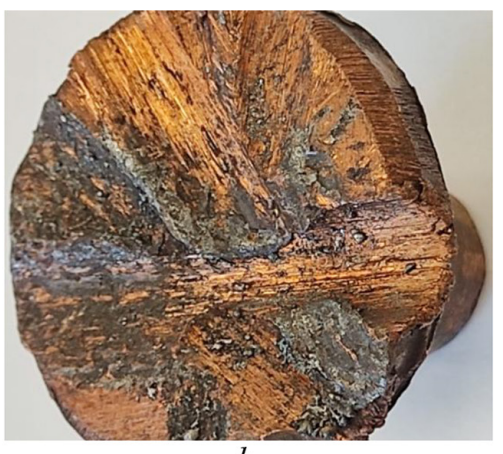

b

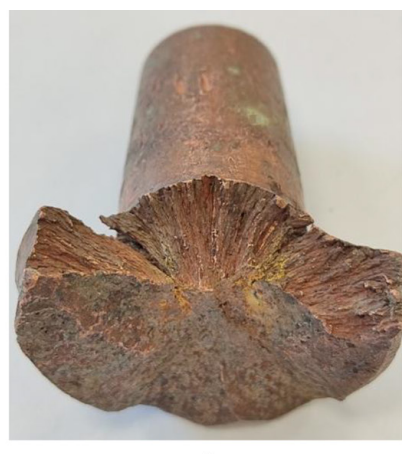

$c$

Рис. 1. Внешний вид электродов после выхода их из строя по причине: $a$ - деформации; $b-$ износа и загрязнения; $c$ - разрушения

Fig. 1. The appearance of the electrodes after their failure due to: $a$-deformations; $b$-wear and contamination; $c$ - destruction

Учитывая эти показатели, сформулирована цель работы: исследовать влияние особенностей технологии изготовления электродов контактной сварки из хромистой бронзы на их механические свойства, электропроводность и структуру.

\section{1. Материалы, оборудование}

\section{и методика проведения экспериментов}

В качестве объекта исследований выбран сплав С 81300 - 82800 [4] системы $\mathrm{Cu}-1,0 \%$ $\mathrm{Cr}-0,05 \%$ P (мас.\%), полученный по разным технологиям:

1. Способ выплавки (табл. 1, образцы 1-4), включающий производство лигатуры $\mathrm{Cu}-\mathrm{Cr}$ и конечного сплава в производственных условиях в виде прутков, и получение из них электродов контактной сварки литьем, холодным прессованием, высокоскоростной штамповкой, токарной обработкой. 
2. Способ выплавки (табл. 1 образец 5), включающий изготовление лигатуры в виде мультикомпонентного элемента - таблетки $\mathrm{Cu}-\mathrm{Cr}$, состоящей из $\mathrm{Cu}-$ матрицы с наноструктурированными частицами $\mathrm{Cr}$, введения ее в расплав меди, заливку в матрицу-штамп с последующей пластической деформацией с целью получения электродов контактной сварки типа D.

Методика проведения исследований по второму способу выплавки предусматривала получение расплава из отходов медного лома типа А 1/1 ГОСТ 54564-2011. Масса загружаемого в графитовый тигель индукционной печи металла составляла 1 кг. Плавку осуществляли под слоем древесного угля толщиной 25-30 мм при рабочей частоте индукционной печи $44 \pm 4$ кГц. Медный расплав раскисляли фосфором, который добавляли в виде лигатуры МФ 9 ГОСТ 4515-93 в количестве 0,5 мас.\%. Затем в раскисленный расплав вводили легирующий мультикомпонентный элемент в виде таблетки (рис. 2), состоящей из базовых элементов: матрицы 0,83 мас.\% медного порошка марки ПМС-1 ГОСТ 4960-2017 и 0,17 мас.\% наноструктурированных частиц хрома Х99 ГОСТ 5905-2004. Для наноструктурирования частиц хрома использовали планетарно-центробежную мельницу ПЦМ-50-НАНО, в которой воздействие больших инерционных сил на мелющие тела и обрабатываемый материал в сотни раз ускоряют помол и приводят к механохимической активации веществ. Размер получаемых частиц не более 100 нм. Смешивание порошков меди и хрома для легирующего элемента осуществляли путем многократного встряхивания в широком закрытом боксе при различных его поворотах. Мультиком-

Таблица 1. Исследуемые образцы электродов (рис. 4) типа D ГOCT ISO 15609-5-2020

\begin{tabular}{|c|l|}
\hline $\begin{array}{c}\text { Образцы } \\
\text { электродов }\end{array}$ & \multicolumn{1}{|c|}{ Способ изготовления электродов из сплава С81300-С 82800} \\
\hline 1 & Первый способ выплавки, литьем \\
\hline 2 & Первый способ выплавки, токарной обработкой \\
\hline 3 & Первый способ выплавки, высокоскоростной штамповкой \\
\hline 4 & Первый способ выплавки, холодным прессованием с термообработкой \\
\hline 5 & Второй способ выплавки, с термообработкой \\
\hline
\end{tabular}

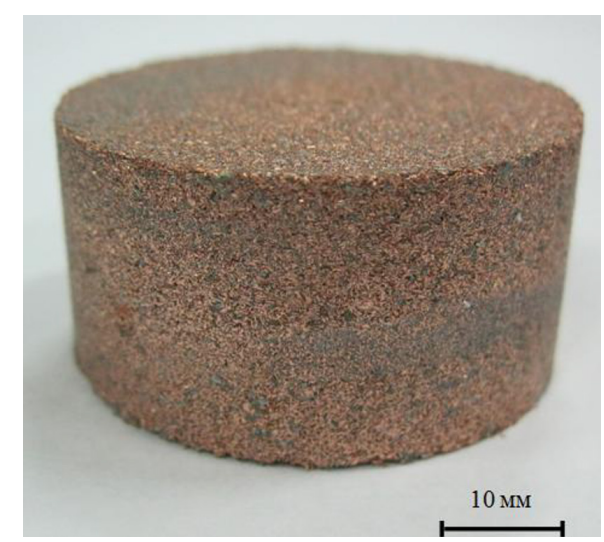

Рис. 2. Легирующий мультикомпонентный элемент

Fig. 2. Alloying multicomponent element 
понентный легирующий элемент в виде таблетки получали холодным прессованием в матрице диаметром 40 мм. Давление прессования 300 МПа, необходимое номинальное усилие пресса

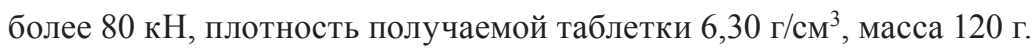

Жидкий металл подвергали воздействию переменного электромагнитного поля с частотной модуляцией тока, повышая частоту на 35-40 Гц от рабочей частоты печи [5]. Это дает возможность перемешивать и получать в индукционной печи однородный по химическому составу сплав.

Технология изготовления электродов включала следующие операции:

- заливку расплавленного металла в подогретую до $420-450^{\circ} \mathrm{C}$ матрицу-штамп технологической оснастки (рис. 3a);

- охлаждение расплава до температуры $850-900{ }^{\circ} \mathrm{C}$ и штамповка прошивкой канала охлаждения электрода с приданием ему конечной формы пуансоном с усилием 950-980 кН (рис. 3b);

- выталкивание электрода из матрицы-штамп в охлаждающую камеру с проточной водой.

Старение электродов производили в муфельной печи СНОЛ-1.62.5.1/11-ИЗ при температуpe $450{ }^{\circ} \mathrm{C}$ в течение 4 ч.

Удельную электрическую проводимость измеряли на микроомметре Ф4104-М1, принцип действия которого основан на измерении величины падения напряжения на измеряемом сопротивлении при прохождении через него оперативного тока заданной величины.

Травление образцов для анализа микроструктуры осуществляли в спиртовом растворе железа хлорного (50 мл $\mathrm{C}_{2} \mathrm{H}_{5} \mathrm{OH}, 2,5$ гр. $\mathrm{FeCl}_{3}$ ). Микроструктуру образцов исследовали на инвертированном металлографическом микроскопе Carl Zeiss Axio Observer MAT. Фрактографические исследования поверхности разрушения изучали на растровом электронном микроскопе HITACHI TM - 1000. Энергодисперсионный микроанализ EDX проводили на растровом электронном микроскопе JEOL JSM-7001F.

Измерение твердости образцов выполняли на твердомере ТP 5014, по шкале твердости F, при величине испытательной нагрузки $\mathrm{P}=588,4 \mathrm{H}$, диаметр шарика 1,588 мм. Измерение микротвердости образцов выполняли на микротвердомере ПМТ-3 при величине испытательной нагрузки $\mathrm{P}=0,098$ Н с интервалом между замерами 150-200 мкм.

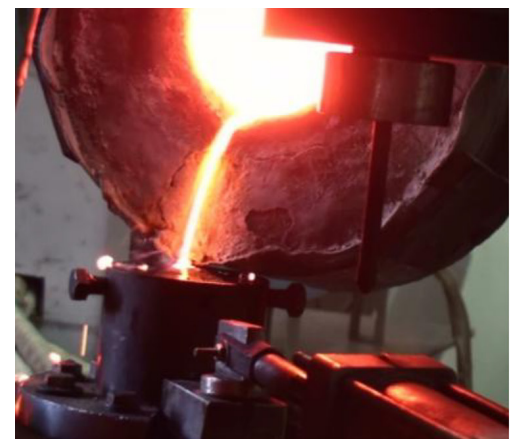

$a$

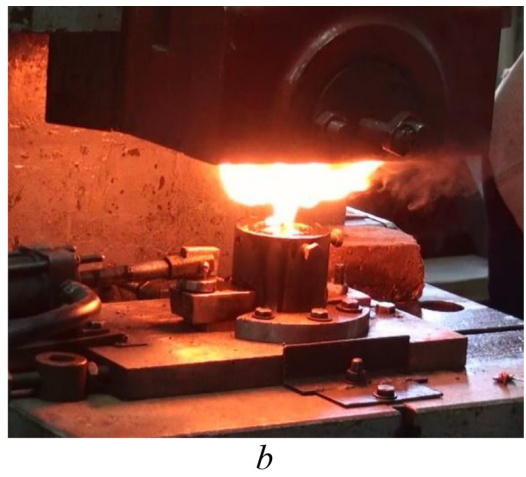

Рис. 3. Технология изготовления электродов: $a$ - заливка в матрицу-штамп; $b$ - штамповка

Fig. 3. Electrode manufacturing technology: $a$ - filling into the die-stamp; $b$ - stamping 

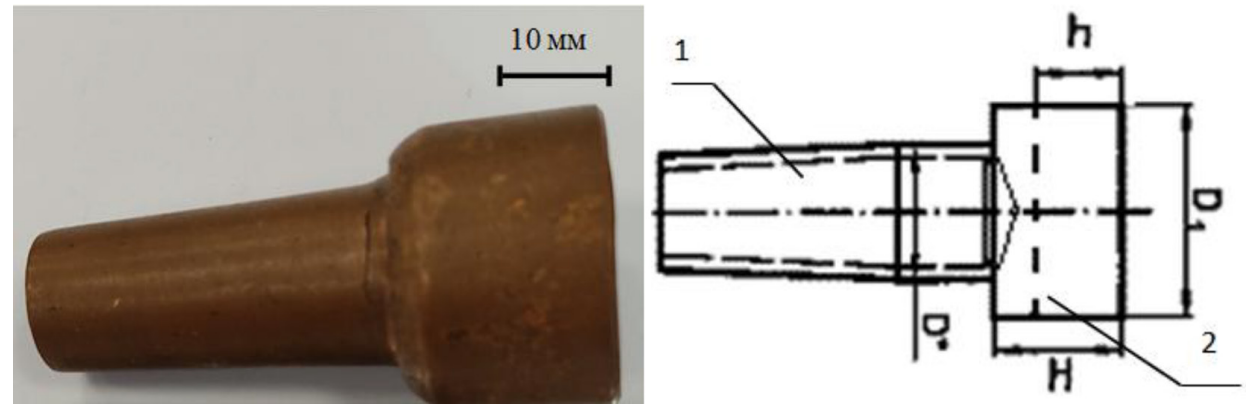

Рис. 4. Электрод контактной сварки типа D: 1 - посадочная часть; 2 - рабочая часть

Fig. 4. Contact welding electrode type D: 1 - landing part; 2 - working part

Таблица 2. Режимы сварки арматуры 10+40 мм

\begin{tabular}{|c|c|c|c|c|c|}
\hline $\begin{array}{c}\text { Усилие } \\
\text { на электродах, кН }\end{array}$ & $\begin{array}{c}\text { Сварочный } \\
\text { ток, кА }\end{array}$ & $\begin{array}{c}\text { Скорость } \\
\text { сварки, т/мин }\end{array}$ & $\begin{array}{c}\text { Время } \\
\text { сварки, с }\end{array}$ & $\begin{array}{c}\text { Относительная } \\
\text { осадка } \\
\text { стержней }\end{array}$ & $\begin{array}{c}\text { Фактический расход } \\
\text { охлаждающей воды, } \\
\text { л/мин }\end{array}$ \\
\hline 5,8 & 23,6 & 30 & $0,25-0,72$ & $0,45-0,6$ & 12 \\
\hline
\end{tabular}

Испытание проводили на контактной машине МПТУ-300. Сваривали вкрест стержни арматуры диаметрами 10+40 мм из сплава G10340-10380 (сталь 35ГС) на режимах сварки (табл. 2).

\section{2. Результаты экспериментов и их обсуждение}

Значения твердости, удельной электропроводности и микротвердости от количества циклов сварки показаны на рис. 5.

$$
\begin{gathered}
\square \text { Твердость НВ } \square \text { Удельная электропроводность } \square \text { Микротвердость HV } \\
\text { в \% от IACS }
\end{gathered}
$$

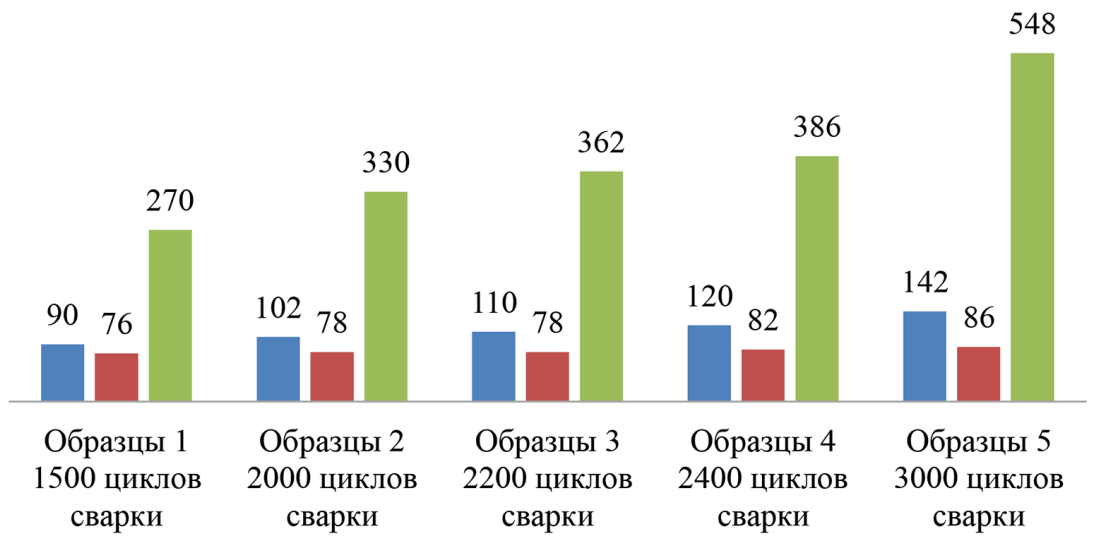

Рис. 5. Значения твердости, удельной электропроводности и микротвердости от количества циклов сварки

Fig. 5. Values of hardness, electrical conductivity and microhardness from the number of welding cycles 
Образцы электродов 1 (табл. 1), при испытании выполнили порядка 1500 циклов сварки, так как имеют невысокую твердость $90 \mathrm{HB}$, микротвердость $270 \mathrm{HV}$ и электропроводность 76 \% IACS (рис. 5). Микроструктура с дендритным строением (рис. $6 a$ ), причем ветви дендритов имеют различную протяженность, что указывает на замедленную скорость охлаждения. Следует отметить, что междендритные участки имеют значительную толщину, а это в свою очередь приводит к снижению стойкости и потере формы рабочей части электродов в процессе эксплуатации (рис. 13a, b).

Исследования, выполненные на электронном микроскопе, позволили выявить наличие дисперсных включений преимущественно глобулярной формы протяженностью 1,5-3 мкм (рис. 7). Микрорентгеноспектральный анализ, выполненный для идентификации типа включений, позволил установить, что это дисперсные интерметаллиды типа $\mathrm{Cu}-\mathrm{Cr}$ (рис. 7a), а также фосфидные включения (рис. $7 b$ ). Наличие фосфидных включений обусловлено технологией получения сплава при его раскислении фосфористой медью.

Образцы электродов 2 (табл. 1) при испытании выполнили порядка 2000 циклов сварки, имеют твердость $102 \mathrm{HB}$, микротвердость $330 \mathrm{HV}$ и электропроводность 78 \% IACS (рис. 5). Микроструктура со строением, характерным для равновесного состояния бронзы, имеет разнозернистость, которая вызвана рекристаллизацией в процессе получения прутков в производственных условиях (рис. $6 b, c$ ). Электроды лучше сохраняют форму, но рабочая часть в процессе проведения эксперимента не износилась на всю длину $\mathrm{h}$ (рис. 4), так как обладает недостаточной твердостью и износостойкостью, из-за чего электроды преждевременно выходят из строя.

Образцы электродов 3 (табл. 1) при испытании выполнили порядка 2200 циклов сварки, имеют твердость $110 \mathrm{HB}$, микротвердость $362 \mathrm{HV}$ и электропроводность 78 \% IACS (рис. 5). Микроструктура - с равноосным полиэдрическим строением зерен (рис. $6 d, e$ ), это обусловлено технологией получения электродов их прутка высокоскоростной штамповкой. Стойкость полученных по этой технологии электродов выше, чем у предыдущих образцов. Однако в большинстве случаев происходит преждевременное выкрашивание рабочей части электрода, что ограничивает срок эксплуатации.

Образцы электродов 4 (табл. 1) при проведении эксперимента изнашиваются практически на всю толщину h (рис. 4), выполняя порядка 2400 циклов сварки, имеют твердость 120 HB, микротвердость $386 \mathrm{HV}$ и электропроводность 82 \% IACS (рис. 5). Микроструктура достаточно однородного строения с наличием небольшого количества включений (рис. $6 f$ ). После термической обработки, включающей в себя старение, происходит повышение прочности и твердости бронзы за счет равномерного выделения интерметаллидов $\mathrm{Cu}-\mathrm{Cr}$. Это приводит к уменьшению легированности твердого раствора, что сопровождается некоторым повышением электропроводности. Электроды обладают хорошей стойкостью и эксплуатационными характеристиками.

Распределение и размер интерметаллидов в образцах электродов 2, 3, 4 имеют идентичный характер. Исследование при больших увеличениях позволило выявить наличие дисперсных включений, размеры которых не превышают 3 мкм (рис. 8).

Микрорентгеноспектральный анализ, выполненный для идентификации типа включений, позволил установить, что эти включения являются интерметаллидами типа $\mathrm{Cu}-\mathrm{Cr}$, распределенными в медной матрице (рис. 9). 


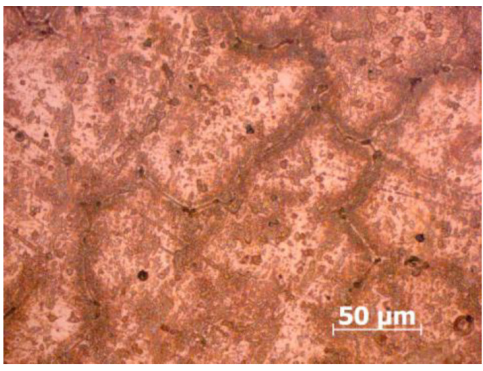

$a$
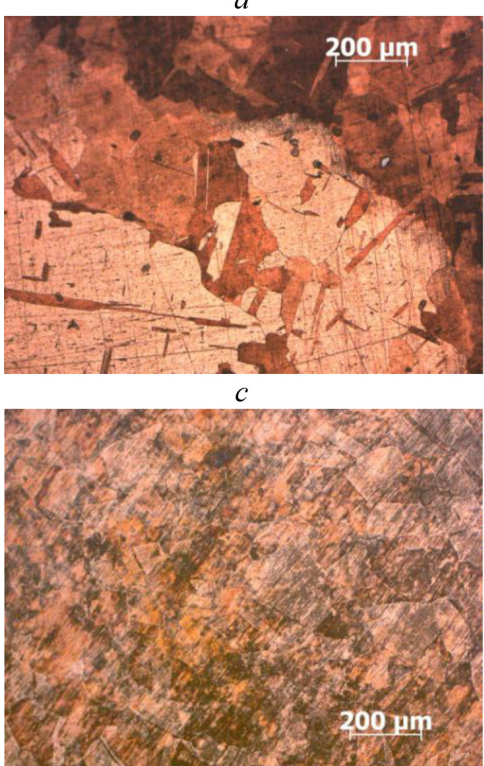

$e$

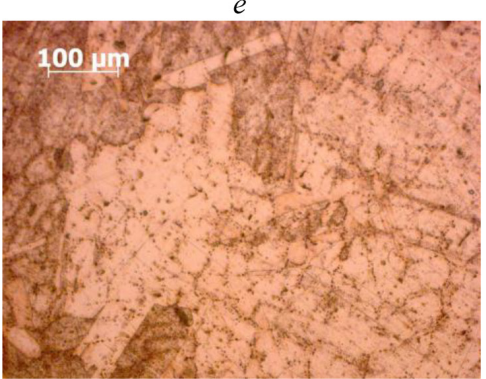

$g$

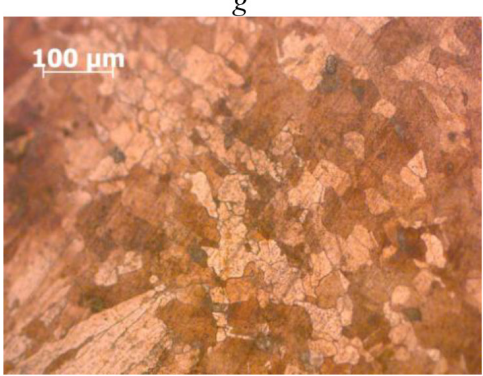

$i$

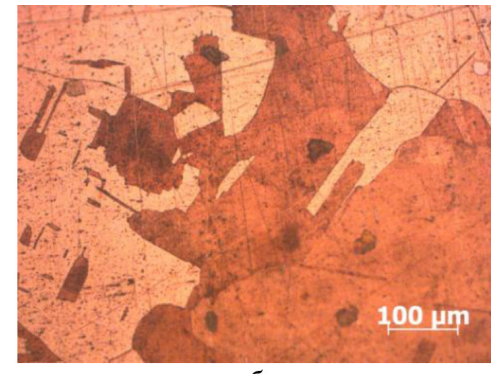

$\sigma$

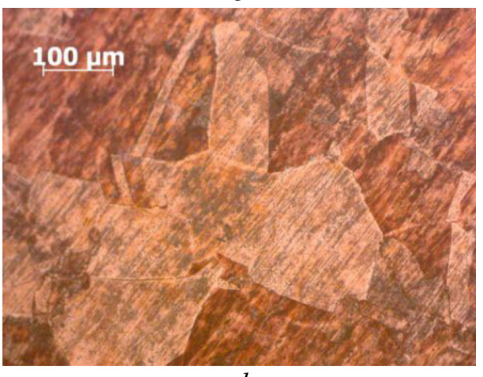

$d$
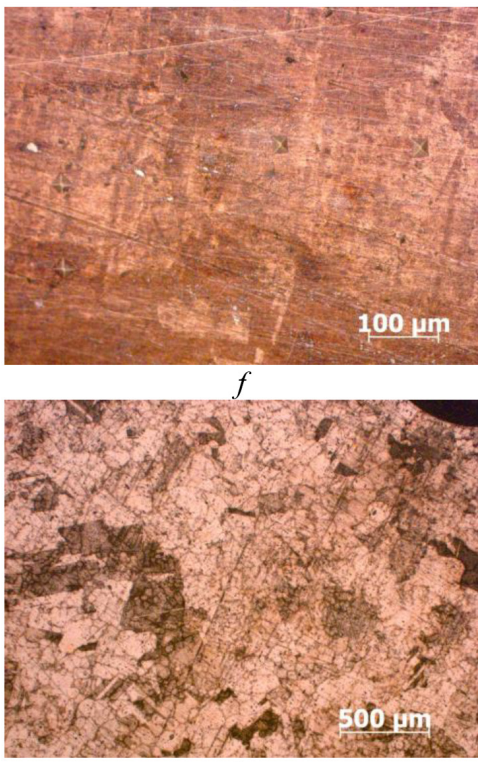

$h$

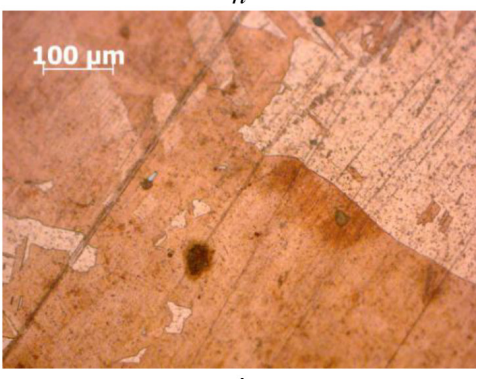

$j$

Рис. 6. Микроструктуры электродов: $a, b$ - образцы электродов $1 ; c, d$-образцы электродов $2 ; e, f-$ образцы электродов $3 ; g, h$ - образцы электродов $4 ; i, j$ - образцы электродов 5

Fig. 6. Microstructures of electrodes: $a, b$-electrode samples $1 ; c, d$-electrode samples $2 ; e, f$-electrode samples $3 ; g, h$-electrode samples $4 ; i, j$ - electrode samples 5 


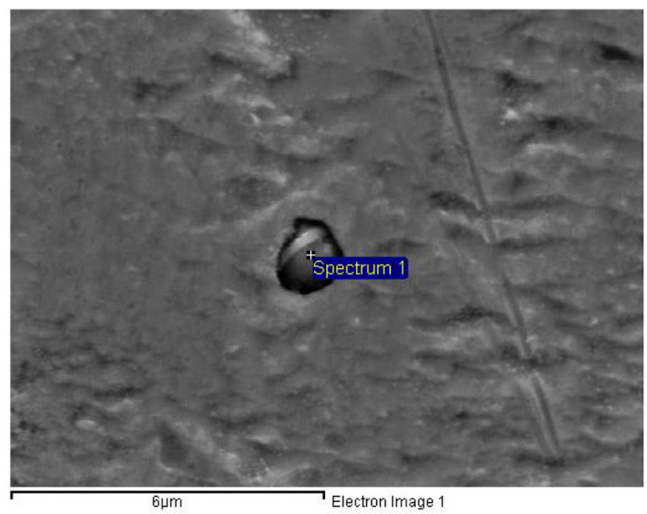

\begin{tabular}{|c|c|c|}
\hline Element & Weight $\%$ & Atomic $\%$ \\
\hline $\mathrm{P}$ & 3.67 & 6.76 \\
\hline $\mathrm{Cr}$ & 96.33 & 93,24 \\
\hline Totals & 100.00 & 100.00 \\
\hline
\end{tabular}

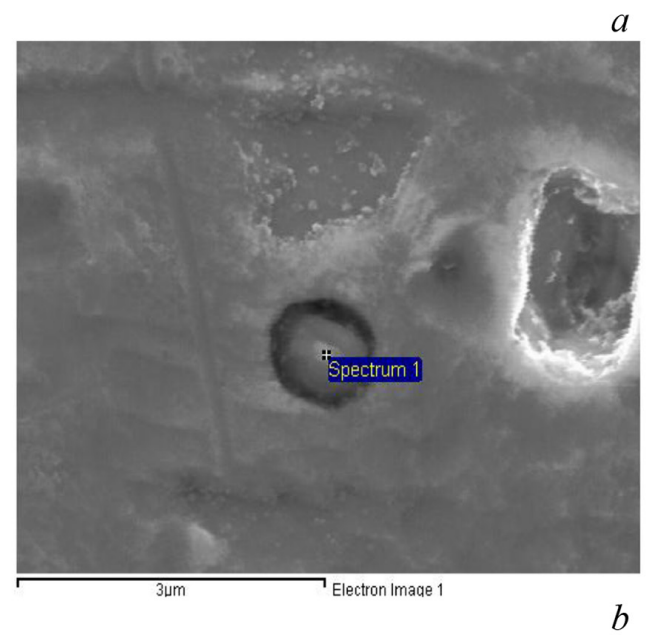

\begin{tabular}{|c|c|c|}
\hline Element & Weight\% & Atomic\% \\
\hline $\mathrm{P}$ & 17.76 & 26.60 \\
\hline $\mathrm{Cr}$ & 82.24 & 73,40 \\
\hline Totals & 100.00 & 100.00 \\
\hline
\end{tabular}

Рис. 7. Микроструктура образцов электродов 1 с наличием фосфидных глобулярных включений: $a, b-$ при разных увеличениях

Fig. 7. Microstructure of electrode samples 1 with the presence of phosphide globular inclusions: $a, b-$ at different magnifications
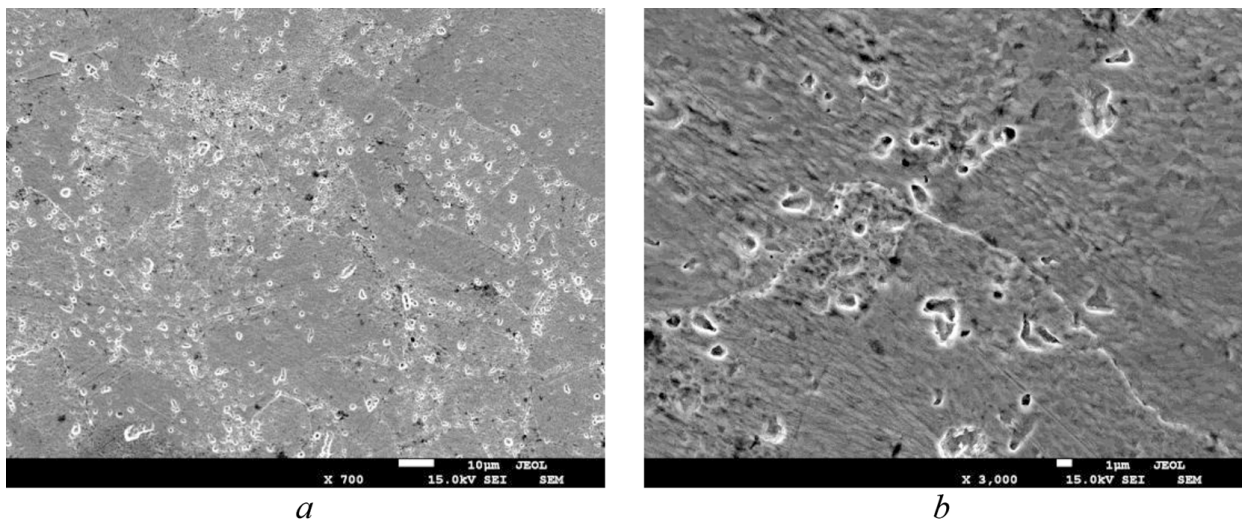

Рис. 8. Микроструктура образцов электродов 4 с наличием дисперсных включений: $a, b-$ при разных увеличениях

Fig. 8. Microstructure of electrode samples 4 with the presence of dispersed inclusions: $a, b-$ at different magnifications 


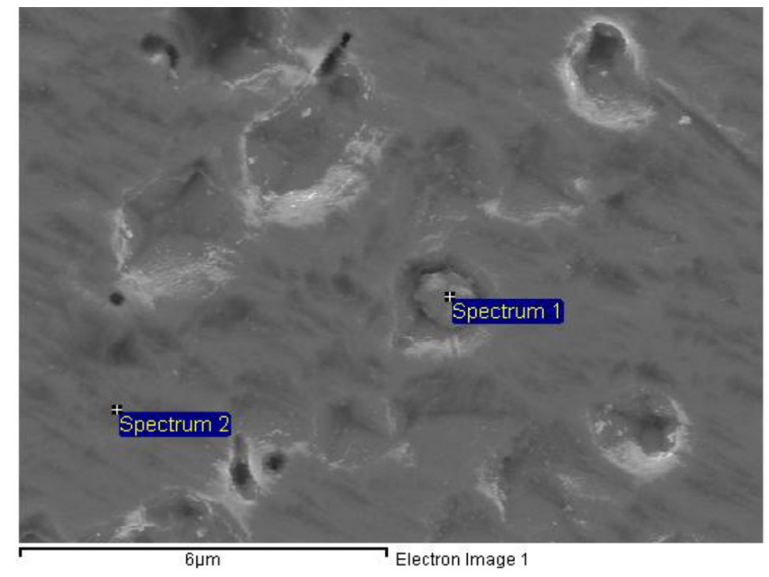

$a$

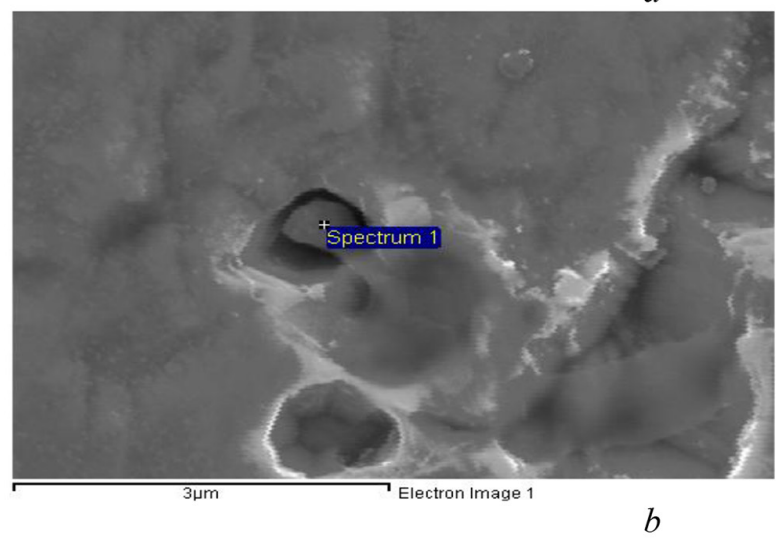

\begin{tabular}{|c|c|c|}
\hline Element & Weight $\%$ & Atomic\% \\
\hline \multicolumn{3}{|c|}{ Spectrum 1 } \\
\hline $\mathrm{Cr}$ & 29.29 & 33.61 \\
\hline $\mathrm{Cu}$ & 70.71 & 66.39 \\
\hline Totals & 100.00 & 100.00 \\
\hline \multicolumn{3}{|c|}{ Spectrum 2} \\
\hline $\mathrm{Cu}$ & 100.00 & 100.00 \\
\hline Totals & 100.00 & 100.00 \\
\hline
\end{tabular}

\begin{tabular}{|c|c|c|}
\hline Element & Weight $\%$ & Atomic $\%$ \\
\hline $\mathrm{P}$ & 2.49 & 4.79 \\
\hline $\mathrm{Cr}$ & 17.90 & 20.53 \\
\hline $\mathrm{Cu}$ & 79.61 & 74.68 \\
\hline Totals & 100.00 & 100.00 \\
\hline
\end{tabular}

Рис. 9. Микроструктура образцов электродов 4: $a, b$ - при разных увеличениях

Fig. 9. Microstructure of electrode samples 4: $a, b-$ at different magnifications

Образцы электродов 5 (табл. 1) при проведении эксперимента изнашиваются на всю толщину h (рис. 4), выполняя порядка 3000 циклов сварки, имеют твердость 142 НВ, микротвердость 548 HV и электропроводность 86 \% IACS (рис. 5). Микроструктура неоднородного строения, наблюдаются участки с дендритным строением, что характерно для литых структур (рис. $6 g, h$ ). На отдельных участках шлифа наблюдаются достаточно мелкие зерна, имеющие равноосное строение со следами пластической деформации (рис. 6i), а также крупные равноосные зерна (рис. 6j). Различие в строении образов электродов 5 обусловлено технологией его получения, которая совмещает процессы литья и деформации. Условия охлаждения различных участков электрода неодинаковы, поэтому в отдельных участках успевают пройти процессы рекристаллизации, что приводит к формированию равноосных зерен, имеющих значительные различия в их размерах. Это определяется протеканием процессов рекристаллизации. Кроме того, следует учесть, что в процессе пластической деформации происходит дробление зерен и формирование текстуры деформации, а ускоренное охлаждение препятствует протеканию вторичной рекристаллизации в отдельных участках (рис. 6i). Следует отметить, что по предлагаемой технологии получения электрода происходит совмещение процессов литья, пластической деформации и закалки. В результате такого комплексного воздействия формируется

$$
-923-
$$


существенно неоднородная структура [11], в которой должна проявляться анизотропия свойств на отдельных участках электрода. Дальнейшая термическая обработка заключается только в старении с целью повышения механических свойств за счет выделения дисперсной интерметаллидной фазы $\mathrm{Cu}-\mathrm{Cr}$. Отмечено, что после старения происходит повышение твердости, а также электропроводности (рис. 5). Электропроводность в образцах электродов 5 имеет наибольшие значения по сравнению с образцами 1-4. Это можно объяснить особенностью микроструктуры и фазовым составом электрода. Можно наблюдать полный износ рабочей поверхности электрода с сохранением формы.

Исследования, выполненные на электронном микроскопе (рис. 10a), позволили наблюдать наличие дисперсных включений округлой формы размерами до 3 мкм.

Микрорентгеноспектральный анализ, выполненный для идентификации типа включений (рис. 10b), позволил установить, что они являются оксидами меди, распределенные в медной матрице. Это, по-видимому, связано с недостаточным раскислением сплава в процессе плавки.

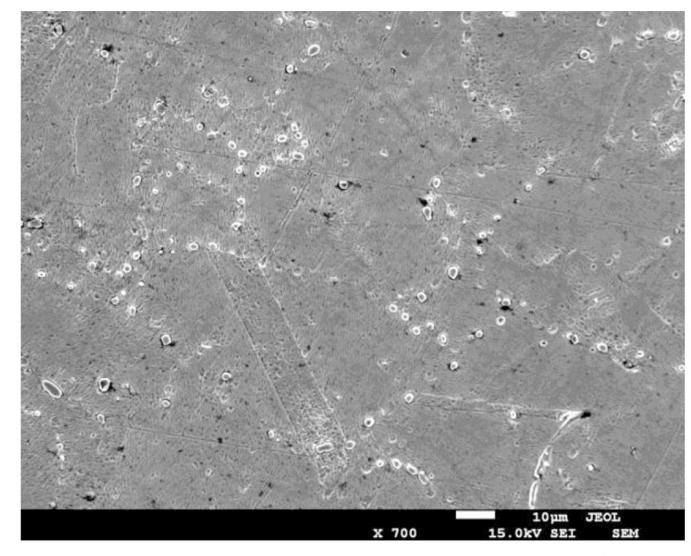

$a$

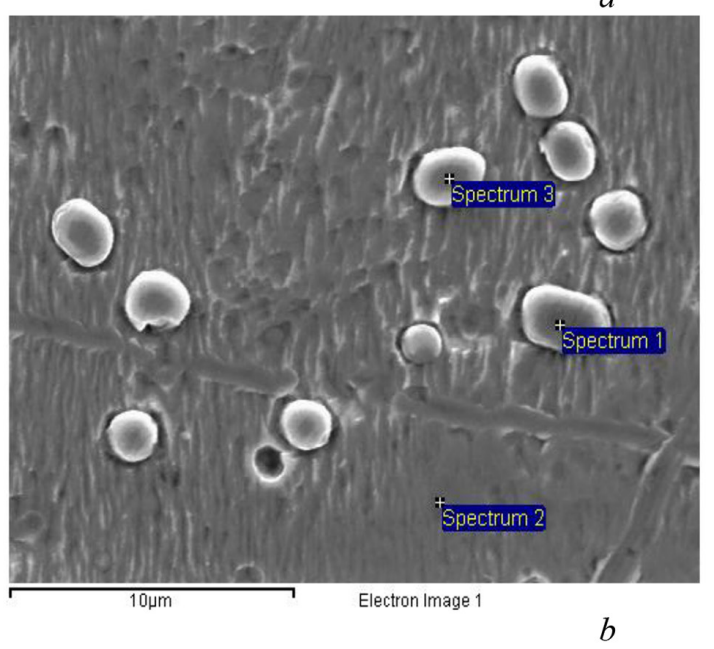

\begin{tabular}{|c|c|c|}
\hline Element & Weight $\%$ & Atomic $\%$ \\
\hline \multicolumn{3}{|c|}{ Spectrum 1 } \\
\hline $\mathrm{O}$ & 9.56 & 29.61 \\
\hline $\mathrm{Cu}$ & 90.44 & 70.39 \\
\hline Totals & 100.00 & 100.00 \\
\hline \multicolumn{3}{|c|}{ Spectrum 2} \\
\hline $\mathrm{Cu}$ & 100.00 & 100.00 \\
\hline Totals & 100.00 & 100.00 \\
\hline \multicolumn{3}{|c|}{ Spectrum 3 } \\
\hline $\mathrm{O}$ & 9.88 & 30.34 \\
\hline $\mathrm{Cu}$ & 90.12 & 69.66 \\
\hline Totals & 100.00 & 100.00 \\
\hline
\end{tabular}

Рис. 10. Микроструктура образцов электродов 5 с наличием оксидных дисперсных включений округлой формы: $a, b-$ при разных увеличениях

Fig. 10. Microstructure of electrode samples 5 with the presence of oxide dispersed inclusions of rounded shape: $a, b-$ at different magnifications 
Однако следует отметить, что этот сплав сохраняет высокую твердость и высокую электропроводность.

Исследование микроструктуры при больших увеличениях позволило выявить наличие дисперсных частиц, размеры которых находятся в пределах 0,2-1 мкм (рис. 11).

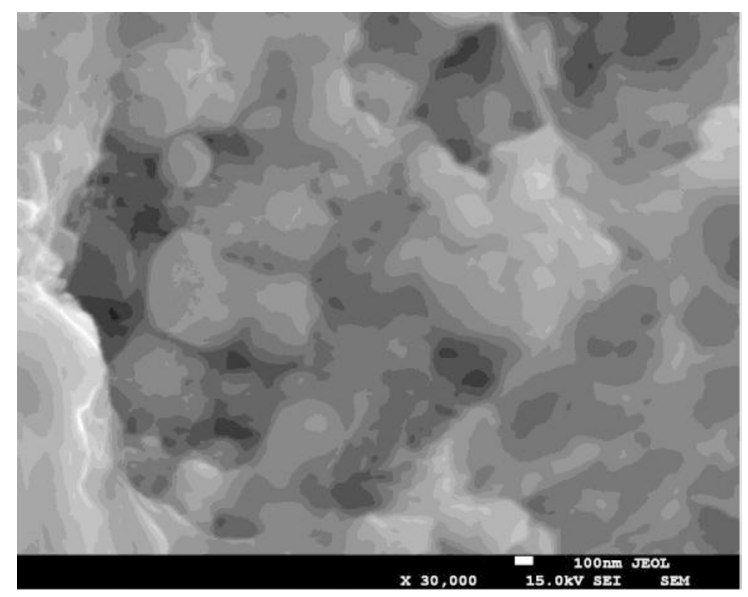

Рис. 11. Микроструктура образцов электродов 5 с наличием дисперсных частиц $0,2-1$ мкм

Fig. 11. Microstructure of electrode samples 5 with the presence of dispersed particles $0.2-1$ microns

Микрорентгеноспектральный анализ, выполненный для идентификации типа включений, позволил установить, что это дисперсные интерметаллиды типа $\mathrm{Cu}-\mathrm{Cr}$ (рис. 12).

В результате производственных испытаний образцов электродов, полученных разными способами (табл. 1), при сварке вкрест арматуры диаметрами 10+40 мм из сплава G10340-10380 (сталь 35ГС) на режимах сварки (табл. 2), был определен основной характер потери работоспособности. Образцы изношенных и разрушенных в процессе эксплуатации электродов представлены на рис. 13. Зависимость степени смятия и износа поверхности электродов от количества рабочих циклов сварки отражена на рис. 14.

\section{Заключение}

1. Разработана технология совмещенного процесса литья и пластической деформации для получения электродов контактной сварки типа $\mathrm{D}$, исключающая дополнительные механические операции по формированию посадочной и рабочей части электродов.

2. Показано влияние технологии получения электродов на их эксплуатационные характеристики. Наиболее высокие характеристики обеспечил способ приготовления расплава с легированием мультикомпонентным элементом в виде таблетки, состоящей из базовых элементов: матрицы 0,83 мас.\% медного порошка марки ПМС-1 и 0,17 мас.\% наноструктурированных частиц хрома Х99.

3. Исследование микроструктуры образцов электродов из сплава С $81300-\mathrm{C} 82800$, полученного по разным технологиям, позволило установить следующее:

- микроструктура определяется способом изготовления электродов;

$$
-925-
$$



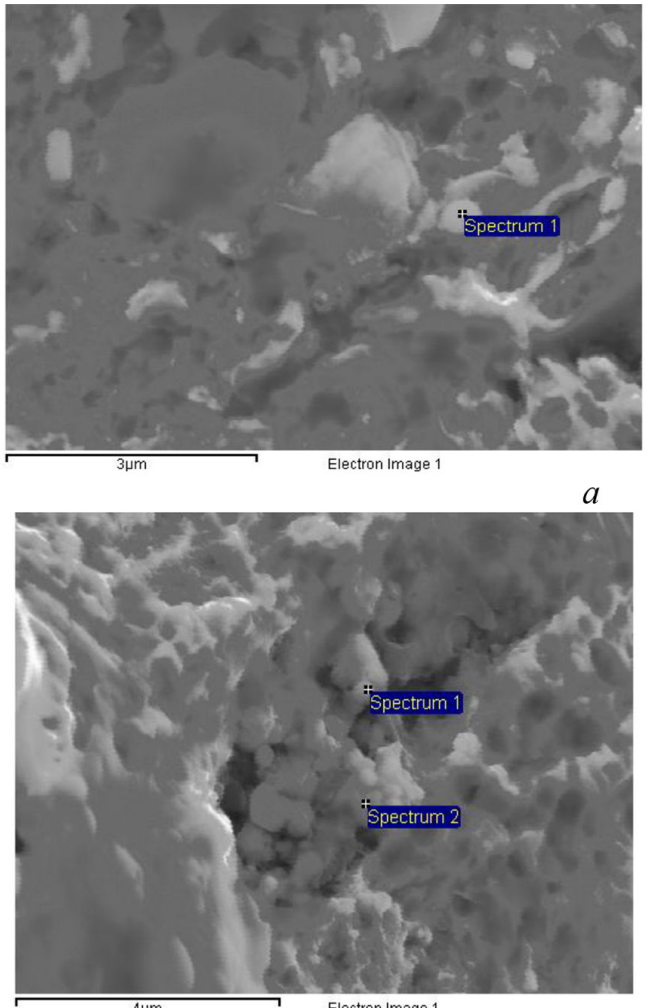

b

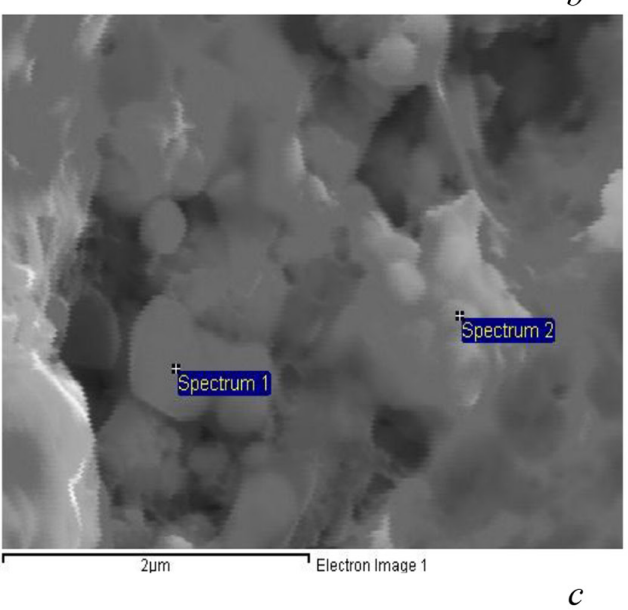

\begin{tabular}{|c|c|c|}
\hline Element & Weight $\%$ & Atomic\% \\
\hline $\mathrm{Cr}$ & 26.13 & 30.18 \\
\hline $\mathrm{Cu}$ & 73.87 & 69.82 \\
\hline Totals & 100.00 & 100.00 \\
\hline
\end{tabular}

\begin{tabular}{|c|c|c|}
\hline Element & Weight $\%$ & Atomic $\%$ \\
\hline \multicolumn{3}{|c|}{ Spectrum 1 } \\
\hline $\mathrm{Cr}$ & 52.80 & 57.76 \\
\hline $\mathrm{Cu}$ & 47.20 & 42.24 \\
\hline Totals & 100.00 & 100.00 \\
\hline \multicolumn{3}{|c|}{ Spectrum 2} \\
\hline $\mathrm{O}$ & 26.21 & 44.66 \\
\hline $\mathrm{Cr}$ & 47.3 & 43.97 \\
\hline $\mathrm{Cu}$ & 26.49 & 11.37 \\
\hline Totals & 100.00 & 100.00 \\
\hline
\end{tabular}

\begin{tabular}{|c|c|c|}
\hline Element & Weight $\%$ & Atomic\% \\
\hline \multicolumn{3}{|c|}{ Spectrum 1 } \\
\hline $\mathrm{Cr}$ & 60.44 & 65.12 \\
\hline $\mathrm{Cu}$ & 39.56 & 34.88 \\
\hline Totals & 100.00 & 100.00 \\
\hline \multicolumn{3}{|c|}{ Spectrum 2 } \\
\hline $\mathrm{O}$ & 21.84 & 40.30 \\
\hline $\mathrm{Cr}$ & 38.64 & 41.34 \\
\hline $\mathrm{Cu}$ & 39.52 & 18.36 \\
\hline Totals & 100.00 & 100.00 \\
\hline
\end{tabular}

Рис. 12. Микроструктура образцов электродов 5 с наличием дисперсных интерметаллидов типа $\mathrm{Cu}-\mathrm{Cr}$ : $a, b, c-$ при разных увеличениях

Fig. 12. Microstructure of electrode samples 5 with the presence of dispersed Cu-Cr type intermetallides: $a, b$, $c$ - at different magnifications 

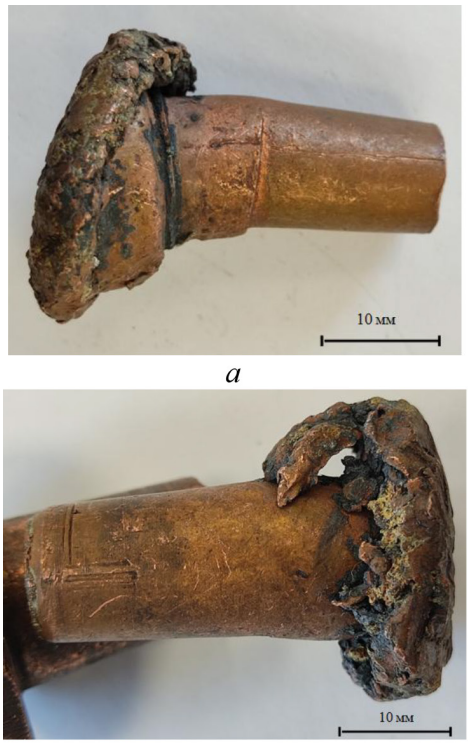

$c$
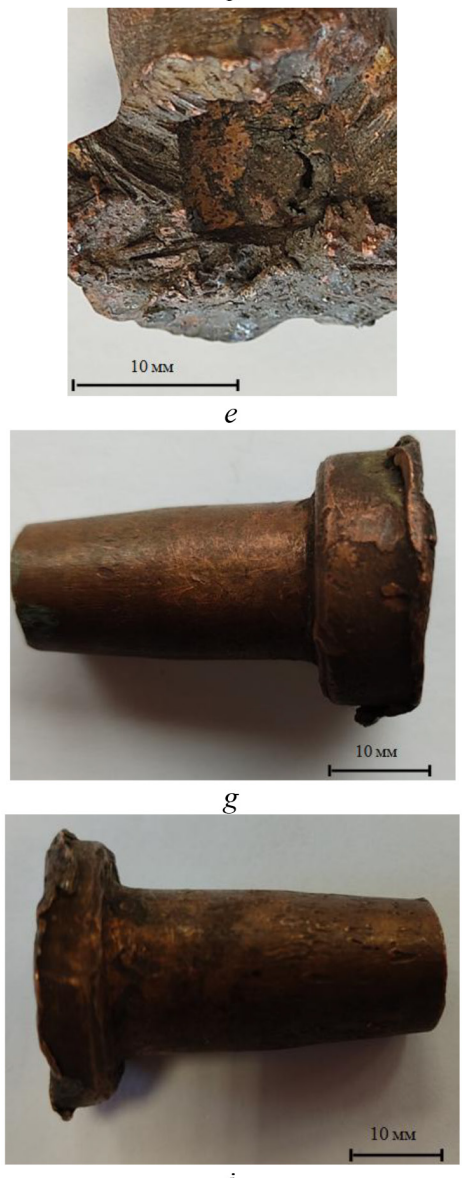

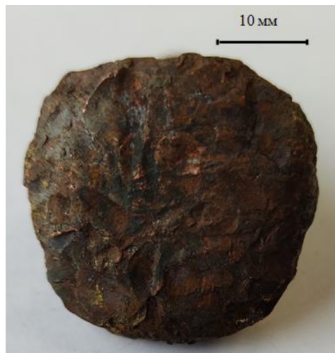

$\sigma$

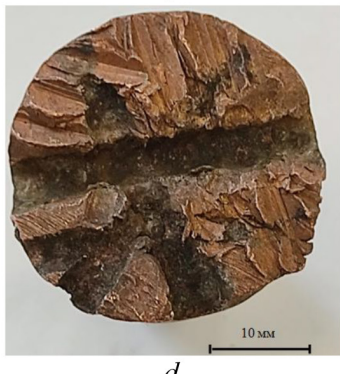

$d$
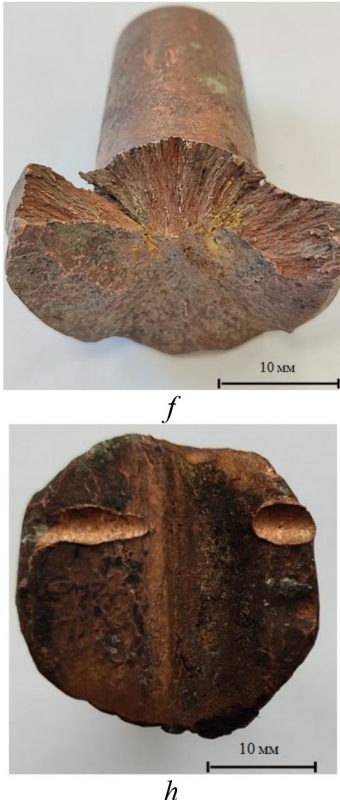

$h$

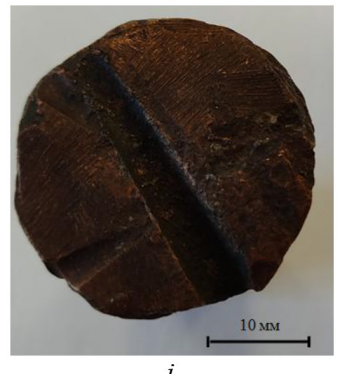

Рис. 13. Образцы изношенных и разрушенных в процессе эксплуатации электродов: $a, b-$ образцы электродов $1 ; c, d$ - образцы электродов $2 ; e, f$ - образцы электродов $3 ; g, h$ - образцы электродов $4 ; i, j-$ образцы электродов 5

Fig. 13. Samples of electrodes worn out and destroyed during operation: $a, b$-electrode samples $1 ; c, d$-electrode samples $2 ; e, f$-electrode samples $3 ; g, h$-electrode samples $4 ; i, j$-electrode samples 5 


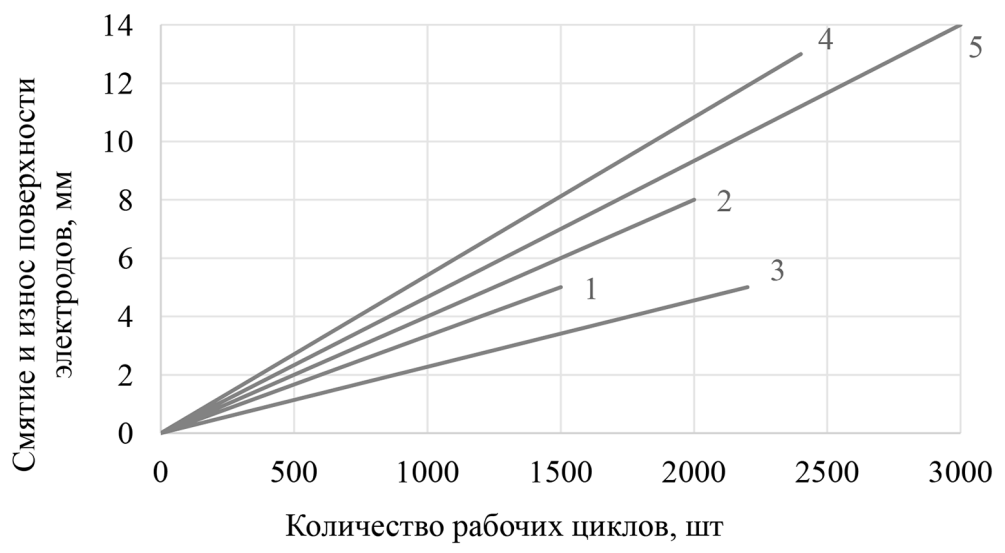

Рис. 14. График зависимости степени смятия и износа поверхности электродов от количества рабочих циклов: 1 - образцы электродов $1 ; 2$ - образцы электродов 2; 3 - образцы электродов 3; 4 - образцы электродов 4; 5 - образцы электродов 5

Fig. 14. Graph of the dependence of the degree of crumpling and wear of the electrode surface on the number of working cycles: 1 - electrode samples $1 ; 2$ - electrode samples 2;3-electrode samples 3; 4 - electrode samples 4; 5 - electrode samples 5

- наиболее благоприятная микроструктура формируется в результате применения совмещенной технологии литья и пластической деформации, а также процессов термообработки.

\section{Список литературы / References}

[1] David Chapman. Copper in Electrical Contacts. Copper Development Association and European Copper Institute. 2015. $21 \mathrm{p}$.

[2] Shyam P. Murarka, Igor V. Verner, Ronald J. Gutmann. Copper-fundamental mechanisms for microelectronic applications. New York: Wiley, Cop. 2000. 337 p.

[3] Hansjörg Lipowsky, Emin Arpaci. Copper in the Automotive Industry. WILEY-VCH Verlag GmbH\&Co. KGaA. 2007. 193 p.

[4] Unified numbering system (UNS) for Copper and Copper Alloys.

[5] Busygin S.L., Tokmin A.M., Dementeva, I.S., Kazakov V.S. The Heating Process in an Induction Crucible Furnace and the Technology of Chromium Bronze Smelting in Order to Obtain Resistance Welding Electrodes. Journal of Siberian Federal University. Engineering \& Technologies, 2018, 11(2), 148-154. DOI: 10.17516/1999-494X-0018.

[6] Xiaojun Sun, Jie He, Bin Chen, Lili Zhang, Hongxiang Jiang, Jiuzhou Zhao, Hongri Hao. Microstructure formation and electrical resistivity behavior of rapidly solidified $\mathrm{Cu}-\mathrm{Fe}-\mathrm{Zr}$ immiscible alloys. Journal of Materials Science \& Technology, 2020, 44, 201-208. DOI:10.1016/j.jmst.2019.10.038.

[7] Bhanudas Bachchhav, Abhishek Kumbhare, Chinmay Hoonur, Sharayu Kulkarni, Jaydeo Kalankar. Grading of Spot Welding Electrode Material Properties Using AHP. Journal of Modern Mechanical Engineering and Technology, 2020, 7, 59-65. DOI:10.31875/2409-9848.2020.07.8.

[8] Ján VIŇÁŠ, Luboš KAŠČÁK, Milan ÁBEL. Analysis of Materials for Resistance Spot Welding Electrodes. 2012, 54(5), 393-397. 
[9] Kang Zhou. Overview of recent advances of process analysis and quality control in resistance spot welding. Mechanical Systems and Signal Processing, 2019, 124, 170-198. DOI:10.1016/j.ymssp.2019.01.041.

[10] Kang Zhou, Lilong Cai. Study on effect of electrode force on resistance spot welding process. Journal of applied physics, 2014, 116(8), 084902. DOI:10.1063/1.4893968.

[11] Jing He, Zhi Zeng, Huabing Li, Shuai Wang. The microstructure and mechanical properties of copper in electrically assisted tension. Materials and Design, 2020, 196, 109171. DOI:10.1016/j.matdes.2020.109171. 